DOI: 10.20472/IAC.2018.035.027

\author{
LÁSZLÓ KOLOSZÁR \\ University of Sopron Alexandre Lamfalussy Faculty of Economics, Hungary
}

\title{
LEAN PRACTICES IN SOME DIVISIONS OF THE HUNGARIAN SME SECTOR
}

\begin{abstract}
:
A strong economy does not exist without an internationally competitive SME sector. But the resources of the SME sector and its management skills are often also limited. By developing this skills, the limited resources available can be utilized more efficiently, so the competitiveness of the companies could be improved. The lean approach as an attitude, common sense, does not require excessive resources, so they can be useful in the SME sector.

This study analyses, how deeply the lean thinking are present in some division of the Hungarian SME sector, and make some comparisons between the divisions. A structured questionnaire was used for data collection. SMEs' representatives, mostly CEOs and managers from some divisions of the Hungarian manufacturing industry participated in the survey.

Out of the results it shows that the level of the lean usage is low among the Hungarian SMEs, so there are development reserves in the usage of lean practices. Strengthening thinking in processes beyond the factory, employee involvement and related leadership development can lead to efficiency gains, but it is important to note that without external experts a wider improvement is not expected. This requires a change of leadership, and state incentives are needed to accelerate this The background of the research method was created to fit the available literature so that to be able to be used in other countries. With that, the available information basis can be expanded with a regional dimension, in case further studies are made.
\end{abstract}

\section{Keywords:}

SMEs, Lean thinking, Lean practices, Hungarian SMEs

JEL Classification: M11, M10, M00 